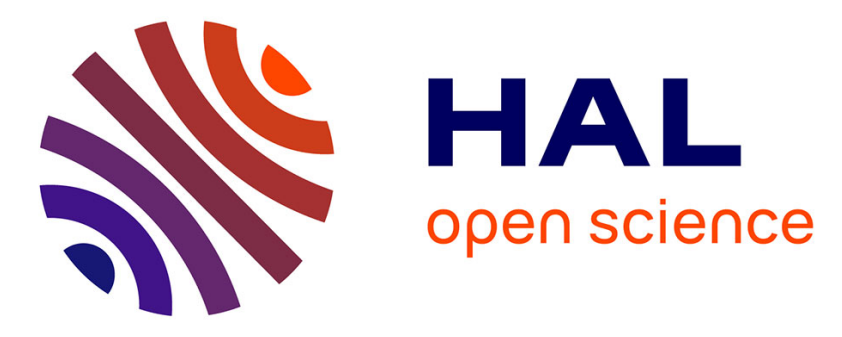

\title{
The Influence of Human Factors on Access and Scheduling of Primary Care Services
}

Jane Guinery, Susan Brown, Martina Berglund, Kezia Scales

\section{To cite this version:}

Jane Guinery, Susan Brown, Martina Berglund, Kezia Scales. The Influence of Human Factors on Access and Scheduling of Primary Care Services. IFIP International Conference on Advances in Production Management Systems (APMS), Sep 2014, Ajaccio, France. pp.547-554, 10.1007/978-3662-44739-0_67. hal-01388593

\section{HAL Id: hal-01388593 \\ https://inria.hal.science/hal-01388593}

Submitted on 27 Oct 2016

HAL is a multi-disciplinary open access archive for the deposit and dissemination of scientific research documents, whether they are published or not. The documents may come from teaching and research institutions in France or abroad, or from public or private research centers.
L'archive ouverte pluridisciplinaire HAL, est destinée au dépôt et à la diffusion de documents scientifiques de niveau recherche, publiés ou non, émanant des établissements d'enseignement et de recherche français ou étrangers, des laboratoires publics ou privés.

\section{(c)(1)}

Distributed under a Creative Commons Attribution| 4.0 International License 


\title{
The Influence of Human Factors on Access and Scheduling of Primary Care Services
}

\author{
Authors - Jane Guinery ${ }^{1, *}$, Susan Brown ${ }^{1}$, Martina Berglund ${ }^{2}$ and Kezia Scales ${ }^{1}$ \\ ${ }^{1}$ Nottingham University Business School, UK \\ \{jane.guinery,s.brown, kezia.scales\}@nottingham.ac.uk \\ ${ }^{2}$ Linkoping University, Sweden \\ martina.berglund@liu.se
}

\begin{abstract}
This paper explores human and organisational factors (HOFs) related to access and scheduling (A\&S) of Healthcare services. Here human factors relate to the 'processed' (patients) as well as the 'processors' (people working in the operation). A 'whole system perspective' is taken to investigate how these influence outcomes. The analysis differentiates acceptable demand on the service from failure demand [1], where failure demand represents unnecessary demand placed on acute care (such as Accident and Emergency in hospitals) as well as primary care services. For eight General Practices in the UK, approaches to practice organisation, including A\&S, are analysed to establish HOFs that influence service delivery and performance. Findings highlight HOFs affecting outcomes and ways in which A\&S arrangements can be modified to improve them. These should inform the choice and management of effective A\&S in a range of Health service scenarios, as well as for General Practices in the UK.
\end{abstract}

Keywords: Human factors. Scheduling. Access. Primary care

\section{Challenges in Primary Care Services}

With a major reorganisation in the National Health Service (NHS) in the UK, transferring the commissioning of healthcare services to Primary Care providers, the need to effectively manage Primary Care has come into sharp focus [2]. In particular there is currently much research on how to reduce levels of referral of patients to acute care in hospitals, where service costs are higher and represent a more serious intervention than in primary care. There have been dual and potentially conflicting responses to this, with multiple Primary care initiatives attempting to manage high levels of demand and shortfalls in health and social service provision through a combination of efficiency driven initiatives (e.g. integration of services; new technologies), and those that rejuvenate traditional practice such as extended opening hours and greater continuity of care (where GPs regularly sees specific patients).

Tensions between a drive towards efficiency and quality of service need to be rationalised. In previous studies on Lean initiatives in healthcare [3], throughput was 
considered the most important focus for improvement, with a qualification that this should be tempered by an appreciation of Healthcare specific issues (including ensuring quality of care). However, this view has been challenged by Seddon et al. [1], who identify that for services (including healthcare), a focus on such measures lacks sufficient critique because not all service activity is value-adding. A 'system' that may appear to be utilising available resources efficiently may in fact be expending effort on activities that are non-value adding, handling failure demand rather than what is required. According to their studies unrecognised 'failure demand', due to an inability of a service to absorb the variety of customer demands, represents the biggest cost associated with services.

In primary care the handling of patient consultations can be operationalised in a variety of ways, and there has been considerable research on appointment systems, taking a 'scientific approach' to optimise performance based on measures that include waiting times and utilisation of clinicians [4]. Such studies make assumptions on 'system' performance that exclude human behaviours (of staff and patients), and do not recognise the varied demands and expectations placed on the service. Despite this shortfall, human and organisations factors (HOFs) have been extensively studied in the context of production planning and scheduling in manufacturing businesses and supply chains $[5 ; 6]$. Here the contribution made by humans in real world situations has been studied in detail and humans have been demonstrated to perform vital roles that enable flexible responses through making effective judgment in situations where information is limited, systems/procedures are in place but problem solving and negotiation is required, and/or where constraints need to be relaxed to support competing demands in complex situations. In such scenarios people can act as gatekeepers, assessing and routing customer requests for services [7]. Based on this, it is anticipated that HOFs will influence the service performance of primary care services as a whole and at an individual level, and HOFs should be influential in the selection of access and scheduling (A\&S) approaches and how they are operationalised.

Further challenges in primary care relate to specific characteristics of the operation inherent to services [8]. In this context they are: simultaneity (the service is consumed as the demand is placed on it); intangibility (the service is experienced and as such the quality of service is difficult to measure); heterogeneity of demand (each customer has a unique combination of requirements and expectations and may need to be 'processed' in different ways); perishability, customers cannot be stored; and 'customers' take part in the service. Additionally the HOFs that need to be taken into account (that influence decision making and action, and ultimately the behaviour of the whole system) relate both to patients who experience the service and take part in it, and to the staff who deliver the service. This increases the complexity of A\&S, as well as making service performance measurement more problematic.

The focus of this paper is on one aspect of an exploratory study investigating organisational aspects of General Practices (Practices) that influence levels of referral to acute care. The aspect of interest is the approach taken to A\&S arrangements and the HOFs that influence their operation and performance. 


\section{Study objectives, scope and methodology}

The original objective of this study was to identify and explore the HOFs in primary care services that influence the level of referrals to acute care. The study collected and analysed qualitative data from interviews in eight General Practices (Practices) in the UK. Practices were purposively selected to be representative, having a variety of characteristics such as list size, resourcing level, location, demographics and approaches to care. In total 48 semi-structured interviews were conducted with Practice staff in a range of roles including General Practitioner (GP), receptionist and nurse. These were transcribed and NVivo used to undertake a thematic analysis [9].

In relation to referrals, A\&S arrangements emerged as a significant theme. Here, 'access' and 'scheduling' are closely related in the way they are defined. Whereas access refers to how patients manage to communicate and obtain appointments with Practice staff including GPs and nurses, scheduling relates more specifically to the decisions made by staff, procedures or systems in relation to how to prioritise and allocate appointments to patients. It is the patients' needs, and in some cases perceived needs, that will place demand on Practice resources. This raises the issue of how Practices should manage the balance between urgent and routine booking of appointments; and in the case of urgent appointments, how the urgency of appointments should be established. Without an appropriate balance patients might be able to book routine appointments in advance but fail to access care in times of acute need; or they may be able to access same-day care but struggle to make appointments to manage their chronic or anticipated health needs. In either case this might lead to a need for hospital acute care due to service failure.

This paper explores this theme; its aim is to scrutinise the alternative A\&S approaches that are employed taking a combined operations management and HOFs perspective. Additional themes complementary to the analysis included: roles (of receptionists, nurses and GPs); referrals to acute care and reasons for them; patient needs, expectations and behaviour; and patient-service interaction. Data on these emergent themes was then analysed to better understand: the role of A\&S arrangements in managing demand; types of failure demand and reasons for their occurrence; the different $A \& S$ approaches that have been employed to meet demand, their objectives, how they are operationalised, and the extent to which they appear to be effective; the influence of HOFs on the choice of approach and outcomes.

\section{The Study of HOFs and Access \& Scheduling Arrangements}

The following sections describe findings and examine their relevance and implications on a topic by topic basis. The topics address, in order: types of failure demand; alternative A\&S arrangements and their relationship to failure demand; HOFs and how they might influence A\&S choices and outcomes; and the receptionist (gatekeeper) role, and how it can be enhanced to support responsiveness. 


\subsection{Types of failure demand and reasons for their occurrence}

The analysis identified a number of types of failure demand. The most substantial, in relation to cost, was patient use of acute care hospital services. This occurred through patient self-referral (at Accident and Emergency or 'A\&E') or GP referral (due to a health crisis). Clearly in many cases these referrals may be necessary, however, in relation to self-referrals many do not translate into treatment or admission and are viewed as 'inappropriate'. According to the qualitative data, Practice staff articulated the following reasons for 'inappropriate' self-referral: patients not being able to access an appointment (for example, lack of GP availability or the Practice being closed); patients calling 111 (an NHS medical hotline) and being told to self-refer to hospital as a precautionary measure; convenience where access to hospital was easier than to the Practice (whether in terms of distance, or patients perceptions that they would be seen more easily). GP referral occurred mainly due to clinical reasons, however in some cases this is a failure demand should the deterioration in a patient's condition be due to delayed access. Other reasons include inadequate support during illness from other health and social care providers. There was also evidence of concerns about limited time and flexibility for patient consultation, and lack of knowledge of a patient's specific conditions (medications and response to treatments, and circumstances) particularly where there was limited provision for continuity of care. These concerns are corroborated by findings from other studies [10].

In relation to failure demand on the Practice, lack of continuity of care is considered to be inefficient as GPs have to refer to notes and ask more questions in consultations and can miss signs of change in patients. This was particularly problematic for more elderly patients with multi-pathologies and medications. Other 'within Practice' forms of failure demand included: underutilisation of GPs and nurses due to patients missing appointments ('did not attend' - DNA); call back time of staff when they cannot respond to patients on first contact; additional consultation time due to patient deterioration; and patient waiting time (in the Practice and in telephone queues). Many of these should be addressed through effective A\&S arrangements and practice.

\subsection{Alternative approaches to $\mathrm{A} \& \mathrm{~S}$ and their effectiveness}

Figure 1 shows how consultations can be booked through the receptionist via telephone or face-to-face, or through online booking. The types of GP consultation available were planned appointments, urgent same day appointments, 'sit and wait' sessions (where patients come at specific times to queue to see the GP), or home visits. An alternative that some Practices employ was for the GP to ring the patient back for a telephone consultation either at a predetermined time (when the GP has purposively reserved time for this), or on an ad hoc basis. Home visits were rarely provided, as they were inefficient due to the travel time involved. Appointments could similarly be made with nurses, who generally undertook more standardised healthcare activities, e.g. monitoring and support of chronic conditions; this provided more time for GPs to handle other priority demands that required their expertise. This and other variables, such as urgency, create a need to carefully channel appointments to both the appropri- 
ate person and form of consultation. Bar web based appointment booking (most applicable to routine appointments), receptionists act as gatekeepers, and it is this role that needs to be understood in relation to what actually occurs regarding A\&S.

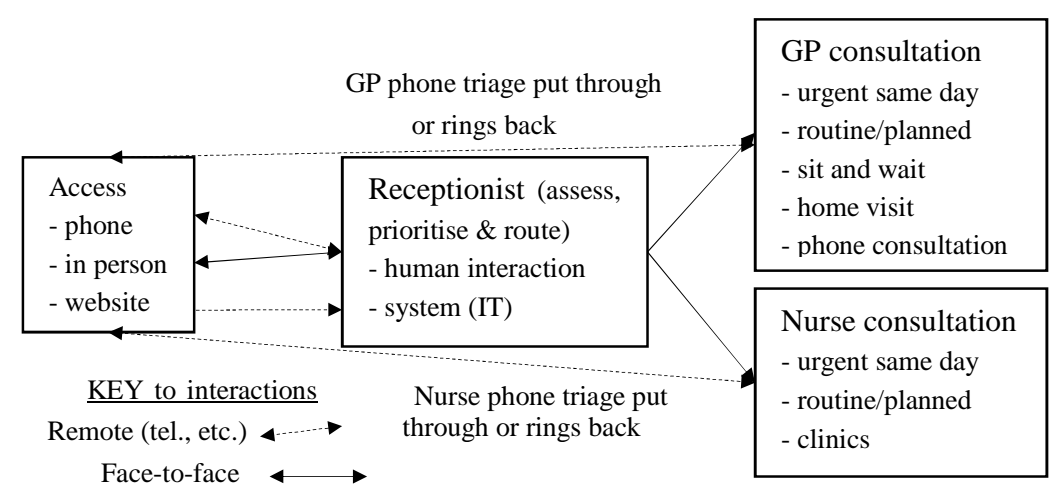

Fig. 1. Access and alternative forms of consultation

The authority for making decisions regarding the urgency of a request from patients is problematic. Clinical triage can be used to alleviate pressure on the receptionist to make clinical judgements. GP or nurse telephone triage was used to differing extents to assess urgency including as a specific access stage where GPs or nurses act as first responder to a patient. In half the Practices receptionists were seen to have some level of autonomy and flexibility in also making access decisions; in others processes were more standardised and the receptionists' authority more limited.

Table 1 shows the different access arrangements available and the associated demand failures. Trade-offs of different arrangements are evident from this, as choices made to improve efficiency may have a negative impact elsewhere. For example arrangements in relation to the mix of routine and urgent appointments vary (see ' $A$ ' in Table 1). One Practice saved 'a majority' of consultation slots to same day appointments, as a way to reduce DNAs. However, as a consequence, handling of priorities is complex as requests pour in at the start of each day. Although this approach may seem to improve the utilisation of GPs, it has specific disadvantages: patient time is lost when making appointments; planned appointments are limited disrupting continuity of care; and, prioritisation is difficult to manage. This can cause anxiety and delays for patients, or deterioration in condition, and may lead to self-referral or a later need for GPs to refer patients to acute care at a much higher cost. Similarly, whilst telephone consultation (see ' $E$ ' in Table 1) seems to be efficient, used in the wrong circumstances it can impact on the quality of consultation as it tends to focus on obvious symptoms rather than holistic care. Multiple forms of service provision in combination (e.g. 'sit and wait' clinics alongside doctor's triage and ring back consultations) were used to satisfy the specific requirements of different patient groups. For example elderly patients may be more able to access or prefer to use 'sit and wait' clinics; advice on medications may be managed effectively through telephone consultation. In 
these cases Practices can be responsive to non-standard demand or situations where standard access arrangements are not effective for all groups. However, not all Practices had these alternatives, and in some the same arrangements acted as an overspill when demand was high, compensating for system inadequacy or lack of capacity.

Table 1. - Alternative access arrangements and associated failure demands

\begin{tabular}{|c|c|c|c|}
\hline ACCESS & ADVANTAGES & DISADVANTAGES & FAILURE DEMAND \\
\hline $\begin{array}{l}\text { A - Limited } \\
\text { planned } \\
\text { appointments; } \\
\text { more same day } \\
\text { appointments }\end{array}$ & $\begin{array}{l}\text { - Perceived reduction in } \\
\text { DNAs } \\
\text { - High service utilisation }\end{array}$ & $\begin{array}{l}\text { - Patients queuing to make appointments } \\
\text { - Implications of FCFS approach, particularly } \\
\text { on specific patient groups, e.g. patient waits } \\
\text { - Continuity of care more problematic }\end{array}$ & $\begin{array}{l}\text { - Patient lost time } \\
\text { - Reception's lost time } \\
\text { - Patient frustration/anxiety }\end{array}$ \\
\hline $\begin{array}{l}\text { B - Pre-booked } \\
\text { appointments }\end{array}$ & $\begin{array}{l}\text { - Easily managed } \\
\text { - Allows continuity of } \\
\text { care } \\
\text { - Less stressful for GPs }\end{array}$ & $\begin{array}{l}\text { - High DNAs as patients forget or no-longer } \\
\text { require appointments } \\
\text { - Registrars (in training) often have to deal with } \\
\text { urgent cases as experienced GPs are booked up! } \\
\text { - May lengthen time to next consultation } \\
\text { - Still need to slot in same day appointments }\end{array}$ & $\begin{array}{l}\text { - Under-utilisation of service } \\
\text { - Potential quality issues around } \\
\text { inexperienced GPs on urgent cases }\end{array}$ \\
\hline $\begin{array}{l}\mathrm{C}-\mathrm{Web}- \\
\text { booking system }\end{array}$ & $\begin{array}{l}\text { - Reduces demand on } \\
\text { receptionists }\end{array}$ & $\begin{array}{l}\text { - Less accessible to non-computer literate } \\
\text { (spaces filled by others), implications of FCFS } \\
\text { Triage not operational! }\end{array}$ & $\begin{array}{l}\text { - FCFS approach may lead to } \\
\text { referrals of others due to poor } \\
\text { prioritisation }\end{array}$ \\
\hline $\begin{array}{l}\mathrm{D}-\text { Sit and } \\
\text { wait }\end{array}$ & $\begin{array}{l}\text { - Same day access for all } \\
\text { patients with perceived } \\
\text { urgent needs } \\
\text { - High service utilisation }\end{array}$ & $\begin{array}{l}\text { - Extra stress for doctors } \\
\text { - Long patient waiting times } \\
\text { - Potentially hasty consultations } \\
\text { - Delays other activities, e.g. home visits } \\
\text { - Continuity of care more problematic }\end{array}$ & $\begin{array}{l}\text { - Quality of consultation may lead to } \\
\text { need for acute care } \\
\text { - Lost time for patients and incon- } \\
\text { venience may lead to self-referral }\end{array}$ \\
\hline $\begin{array}{l}\text { E - Overspill } \\
\text { triage ring back } \\
\text { or consultation }\end{array}$ & $\begin{array}{l}\text { - Supports urgent cases } \\
\text { and improves access } \\
\text { - Efficient on GP time }\end{array}$ & $\begin{array}{l}\text { - Needs informed management \& processes } \\
\text { - Reduced thoroughness of consultation if not } \\
\text { appropriate category }\end{array}$ & $\begin{array}{l}\text { - Risk of ineffective consultation } \\
\text { may lead to need for GP acute care } \\
\text { referral }\end{array}$ \\
\hline $\mathrm{F}$ - Home visits & $\begin{array}{l}\text { - Patient confidence } \\
\text { - Holistic view of needs } \\
\text { - Enables very ill } \\
\text { patients to receive care }\end{array}$ & $\begin{array}{l}\text { - High level of resourcing; may be conducted by } \\
\text { nurses to reduce this }\end{array}$ & $\begin{array}{l}\text { - Lost time for GPs in travelling to } \\
\text { patients' homes }\end{array}$ \\
\hline $\begin{array}{l}\mathrm{G}-\text { Nurse } \\
\text { appointments }\end{array}$ & $\begin{array}{l}\text { - Holistic view of needs } \\
\text { - Less costly resource }\end{array}$ & $\begin{array}{l}\text { - Only considered appropriate for those with } \\
\text { more standard chronic conditions }\end{array}$ & $\begin{array}{l}\text { - No apparent failure demand } \\
\text { associated with these }\end{array}$ \\
\hline
\end{tabular}

\subsection{How HOFs influence access arrangement choices and outcomes}

The heterogeneity of the population impacts on the types of demand placed on primary care for different types of resource and interaction, the corresponding routes followed by patients, and their ability to access the service and make use of it. Looking at the needs of different patient groups it is evident that the 'first-come-firstserved' (FCFS) approach to scheduling can be very problematic, particularly as opportunities for access are not equal for all patient groups. For example, where access is through websites and telephone systems, this requires particular competences and equipment. Similarly, some groups' attitudes and expectations may mean that they communicate their needs less or more effectively. Some patients will also require different lengths of consultation, or prefer continuity of care; physical access including transportation may also be more problematic. More standardised A\&S arrangements may not be able to recognise or take this into account. There is, therefore, a need for more flexibility to adjust appointment lengths and reserve slots for specific categories of patient and types of demand on the service. Whilst some patients may overstate, others may understate or not appreciate the urgency of their need, and nonmedical staff may feel unable to offer opinions. The type of consultation that should 
be offered will also vary and needs to be discerned; the patient might have a new episode requiring diagnosis, or require general advice on chronic disease management. In these cases the appropriateness of nurse appointments or telephone consultation needs to also be decided. The heterogeneity of demand and inability to customise means that some patients may inadvertently be restricted in their ability to access services, due to: limited use of technology (e.g. telephone redial), reluctance to "bother the GP', poor communication skills, and a perceived need to see the same GP.

\subsection{The role of the gatekeeper}

Patient demands are assessed, prioritised and routed in different ways dependent on the nature of the demand and the individual requesting the service. It was the gatekeeper's role to perform this relatively complex task. Their role in some Practices was also to reassure patients, reducing their anxiety and enabling the patient to assess and potentially manage their own condition. Sensitive and timely interactions can build the trust of patients. In these areas the human contribution in the gatekeeping role is particularly important. To prevent failure demand it is important to distinguish between types of demand placed on a service that can be handled in a standard way and those requiring non-standard attention [1]. Receptionists can attempt to differentiate these, in some cases supporting patients as they make an access decision. In some Practices this level of engagement was discouraged, with Receptionists allocating appointments based solely on a patient's perception of urgency, and often without recourse to others. However, active assessment of patients' situations was encouraged in other Practices. In these cases receptionists worked in a more autonomous and flexible way, frequently calling for input from GPs or handling aspects of an enquiry based on their own knowledge and capability (e.g. where trained to differentiate urgent and non-urgent situations). It was apparent that their ability to support patients depended not just on this empowerment, but also on the availability of appointments and the choice, flexibility and responsiveness of the arrangements, e.g. in one Practice, GPs were provided with extra time for consultations (including via telephone) and to be more accessible to other staff in the Practice, including receptionists.

\section{Conclusion}

This empirical research has identified different forms of failure demand associated with $A \& S$; where and how HOFs (related to patients and staff) impact on A\&S; and, the implications of this on the approaches that can be taken to A\&S. Although data is drawn solely from UK General Practices, it has identified important aspects of A\&S that may also be relevant in other health service contexts. Findings demonstrate that it is both the heterogeneity and 'non-specific' nature of demand that makes A\&S problematic, and the need to recognise this when considering alternative ways in which demand can be handled. Implications of not doing so are illustrated through the failure demand types associated with $\mathrm{A} \& \mathrm{~S}$ alternatives. In relation to how $\mathrm{A} \& \mathrm{~S}$ might be improved, different forms of service delivery in combination have been demonstrated 
to address the variety of patient demands placed on them. Also, the receptionist's gatekeeper role has been found to be central in effectively prioritising and routing patients. We can postulate that to deliver a customised response and support a variety of needs, distinct cohorts of patients may need to be identified and communicated with differently either on an $a d$ hoc or systematic basis so that appointments can be prioritised and delivered in different ways. Receptionists, as gatekeepers to the service, need to provide a range of standardised and customised responses; and their capabilities and organisational arrangements that support or inhibit them are pivotal to effective service delivery. To be flexible enough to handle heterogeneous demand and reduce failure demand it is apparent that complementary A\&S approaches, gatekeeper roles, forms of service delivery, and sufficient resources need to be in place.

The study findings question any over simplification and assumptions made that exclude HOFs in the evaluation and selection of A\&S approaches. HOFs provide an additional dimension to understand $\mathrm{A} \& \mathrm{~S}$ arrangements and their subsequent performance, and this dimension needs to be included when exploring system alternatives. Related failure demand explained by HOFs can be expensive and must be factored into any $\mathrm{A} \& \mathrm{~S}$ assessment (including models and simulations) and in choices made by healthcare practitioners when selecting, managing and implementing A\&S systems.

\section{References}

1. Seddon, J., O’Donovan, B.: Rethinking Lean Services. Process Excellence Network, http://www.systemsthinking.co.uk/6-brendan-jul09.pdf accessed <14-052014>(2009)

2. Goodwin, N., Dixon, A., Poole, T., Raleigh, V.: Improving the Quality of Care in General Practice. King's Fund Institute. (2011)

3. Walley, P.: Designing Accident and Emergency Systems: Lessons from Manufacturing. Emergency Medical Journal. 20, 126-130 (2003)

4. Gupta, D., Denton, B.: Appointment Scheduling in Healthcare: Challenges and Opportunities. IIE Transactions. 40, 9, 800-819 (2008)

5. MacCarthy, B.L.; Wilson, J.R. (eds.): Human Performance in Planning and Scheduling, Taylor and Francis (2001)

6. Fransoo, J.C., Wafler, T., Wilson, J.R. (eds.): Behavioral Operations in Planning and Scheduling. Springer publications, Heidelberg (2011)

7. Berglund, M.; Guinery, J.; Karltun, J.: The unsung contribution of production planners and schedulers at production and sales interfaces". In: Fransoo, J.C., Wafler, T., Wilson, J.R. (eds.): Behavioral Operations in Planning and Scheduling,. pp. 47-81. Springer, Heidelberg (2011)

8. Lovelock, C., Gummesson, E.: Whither services marketing: in search of a new paradigm and fresh perspectives. Journal of Service Research. 7, 1, 20-41 (2004)

9. Guest, G., MacQueen, K.M., Namey, E.E.: Applied Thematic Analysis. Sage publications, Inc (2012)

10. Wilson, A., Childs, S.: The relationship between consultation length, process and outcomes in general practice: a systematic review. British Journal of General Practice. December, 1012-1020 (2002) 